\title{
Competência ética, atenção e educação
}

\author{
Ethical competence, attention and education
}

Adriano Rodrigues Ruiz* Universidade do Oeste Paulista

Resumo Este artigo relata a pesquisa bibliográfica sobre a competência ética em ambientes escolares. Partiu-se da concepção de ética como a sabedoria diante de situações cotidianas, na interação da pessoa com si própria e com o mundo. Considerou-se a orientação epistemológica como determinante das relações éticas e encaminhou-se a discussão a partir de dois eixos: um que entende ser o humano determinado pelo ambiente; e, o outro, que o concebe como construtor do mundo e de si próprio. Concluiu-se que a crença no poder do ambiente fomenta o espírito ético da padronização; enquanto isso, na perspectiva centrada na ação do sujeito, a competência ética surge como não pertencente aos conteúdos ensináveis, mas como algo que se aprende praticando: valorizando o olhar atento que busca ver e compreender o mundo.

PALAVRAS-CHAVE: Competência ética; Aprendizagem da atenção; Orientação epistemológica.

Abstract This article presents a bibliographical research about ethical competence in school environment. We started from the concept of ethics as wisdom towards daily interactions with oneself and with the world. We considered epistemological orientation as determinative on ethical relations and it discusses it based on two cores: the first understands human being determined by the environment; the second conceives the human being as a world and itself constructor. We conclude that beliefs into the environment power promote the ethical spirit based on standardization. On the other hand, the perspective towards the subject, ethical competence arises, as it does not belong to the universe of teaching matters, but as something that can be learned by doing it, valuing attentive look trying to see and understand the world.

KEYWORDS: Ethical competence; Attention learning; Epistemological option. 


\section{Introdução}

Essa reflexão, construída a partir de revisão bibliográfica, toma por objeto de estudo o senso ético cultivado - ou a ser cultivado - em contextos educacionais. $\mathrm{Na}$ perspectiva adotada, tendo por aporte epistemológico a biologia do conhecer (MATURANA; VARELA, 1995), pensamos no comportamento ético como próprio de um sujeito que preza o autogoverno e suas decorrências. Vários pensadores trazem concepções acerca de competência ética nessa ótica.

Varela (1995) argumenta que a ética se aproxima mais da sabedoria do que da razão, sendo que o saber-fazer ético emerge do confronto direto com a realidade, estando implicado na prontidão para agir em respeito ao que é justo e virtuoso. Partindo da perspectiva desse autor, Kastrup (2008, p. 124) assevera que a competência ética "é adquirida em contextos específicos, não sendo baseada numa razão universal".

Em seu livro Ética para meu filho, Savater (1996) identifica a ética como a arte de viver, o resultado de um saber-viver que nos permite acertar. E completa dizendo que, ao contrário de outros seres, "podemos inventar e escolher, em parte, nossa forma de vida” (SAVATER, 1996, p. 31).

Jacquard (1990) considera a ética como a sabedoria que nos orienta quando tomamos decisões sobre o nosso comportamento. Ele argumenta que, no jogo da vida, em seu ponto de partida há um espermatozoide e um óvulo, que possuem toda a sabedoria para construir, tão-somente, o nosso corpo: o formato do rosto, a cor da pele, o grupo sanguíneo, a estatura... Fica faltando a construção da pessoa.

Essas concepções de competência ética implicam a existência de um sujeito autônomo em suas escolhas, ciente da responsabilidade que lhe traz a liberdade da tomada de decisões. Cabe à educação formal exercer o papel importante na formação desse sujeito, daí a responsabilidade da escola na escolha de seus aportes epistemológicos. Alvarado (2007) esclarece que educação e epistemologia sempre estão ligadas, sendo a primeira, determinada pela segunda.

Tomando por norte o papel determinante da orientação epistemológica na tessitura das relações educacionais, encaminhamos nossas argumentações sobre competência ética, valendo-nos de dois eixos epistemológicos: o primeiro com raízes nas postulações que mostram o humano construído a partir de fora, pelo ambiente circundante; o outro que concebe o humano como construtor do mundo e de si próprio.

Três eixos forneceram norte para nossas argumentações que apresentaremos a seguir: a vida ética a partir das epistemologias ambientalistas; o desafio de se repensar caminhos epistemológicos e éticos; a renovação dos olhares ao cotidiano, à atenção e à competência ética.

\section{A vida ética a partir de epistemologias ambientalistas}

A predileção da cultura escolar é pelas epistemologias que apresentam traços do espírito ambientalista, em que se entende a sociedade precedendo ao indivíduo. 
Sob esse olhar, o todo - a sociedade - é um ser que modifica os indivíduos, moldando -os. Por essa trilha, educar é conduzir os mais jovens a se adaptarem à sociedade.

Atenta a essa postura, Cervantes (2014) destaca que precisamos reconhecer que vigora nos espaços escolares uma forma de agir, na qual se valoriza a competência, o exterior e as aparências, em contraposição ao desejável que seria uma prática marcada pela valorização do outro, da outra, a empatia, a cooperação, a contemplação da beleza e a harmonia com a natureza.

A valorização da exterioridade gera uma cultura que levou Morin (1991) e Savater (1996) a afirmarem que adotamos a ética da obediência à moda e da normalidade. Eles apontam que somos adeptos de comportamentos que privilegiam o indivíduo-padrão e as atitudes tidas como normais. Por esse caminho pouco iluminado, se legitima aquilo que todos fazem, que está na moda.

Compatível com essa perspectiva ética - alicerçada na exterioridade -, nos domínios escolares, a mente humana é concebida predominantemente como algo similar a um computador: dependente de programação e aberta para o armazenamento de múltiplas informações. Para Varela, Thompson e Rosch (1993, p. 169), isso é uma herança do cognitivismo que considera a inteligência, inclusive a humana, assemelhando-se "de tal modo à computação nas suas características essenciais que a cognição pode realmente ser definida como processos computacionais baseados em representações simbólicas".

Assumindo essa ênfase, a educação parece esquecer que o "organismo e ambiente embrulham-se um com o outro e desembrulham-se um do outro na circularidade fundamental que constitui a própria vida" (VARELA; THOMPSON; ROS$\mathrm{CH}, 1993$, p. 281). Com isso, alimenta o processo pedagógico que, com sabedoria, foi chamado por Paulo Freire (1981, p. 66) de educação bancária: "a educação se torna um ato de depositar, em que os educandos são os depositários e o educador o depositante". Nesta visão, "não há criatividade, não há transformação, não há saber. Só existe saber na invenção, na reinvenção, na busca inquieta, impaciente, permanente, que os homens fazem no mundo, com o mundo e com os outros. Busca esperançosa também" (FREIRE, 1981, p. 66).

O sistema educativo é, sob o olhar de Jacquard (1996, p.123), "o melhor exemplo da nossa timidez perante nós próprios, timidez que nos leva a trair-nos", pois, cada homem não é um ator encarregado de desempenhar um papel de há muito escrito e já desempenhado por muitos outros; "é um autor, tem de escrever o papel que desempenhará"(JACQUARD, 1996, p. 123).

Preocupado com essa timidez, Krishnamurti denuncia:

O Estado soberano não quer que seus cidadãos sejam livres, que pensem por si mesmos, e os controla por meio da propaganda, por meio de falsas interpretações da história, etc. É por isso que a educação se está tornando cada vez mais um meio de ensinar o que pensar e não como pensar. (KRISHNAMURTI, 2001, p. 80-81). 
O próprio Krishnamurti acrescenta que a educação convencional dificulta o pensar independente e que a padronização do homem o conduz à mediocridade. Ao ensinar o que pensar, a escola forma leitores da sua palavra. Nesse contexto, Delval (1998, p. 24) alerta que não devemos nos esquecer de que cabe à escola, como missão histórica fundamental, "formar indivíduos submissos e que aceitem a ordem social dominante sem deixar que ela se modifique".

Com angústia similar, Jacquard (1990, p. 174) lembra-nos de que, em seu esforço para a produção em série de pessoas conforme os padrões, "a escola serve quase sempre para inserir cada um numa via onde repita docilmente as respostas, encontradas desde há muito por outros, a perguntas que não fez". No mesmo sentido, Briggs e Peat (2000, p. 30) advertem: "o risco que todos corremos é de nos tornarmos como cães de Pavlov - com glândulas reagindo a cada toque de sino. E a sociedade é cheia de sininhos".

$\mathrm{Na}$ verdade, o compromisso com a padronização - característico da ética do respeito à moda - tem ajudado a consolidar uma educação desesperançada, pobre em instrumentos intelectuais para o autogoverno e para a construção de utopias. O pesado fardo, repleto de lições que ocultam nossa vocação para a autoria, impõe a caminhada por sulcos traçados pelos que nos antecederam. Assim, continuamos carregando verdades de outras épocas, de outros espíritos científicos, de outros horizontes. Elas anunciam racionalidades, sonhos e pesadelos que já se perderam na sucessão das construções intelectuais da humanidade.

O culto à adaptação encerra em si o louvor ao grupo e a negação da individualidade, como Freitag (1999) denuncia: vivemos a época em que o politicamente correto é a valorização do grupo em face do indivíduo. Cria-se, assim, terreno fértil para a formação do homem objeto, do homem fragmento da massa.

Ao discorrer sobre o empobrecimento gerado pela negação da individualidade, Krishnamurti (2001, p. 15) alerta que existe tanto a ação coletiva quanto a individual, a de massa tornou-se "um meio de fuga conveniente para escapar da ação individual". Quando não entendemos "a relação da verdadeira ação é que nos voltamos para a abstração chamada massa e, por isso, nos tornamos irresponsáveis em nossa ação" (KRISHNAMURTI, 2001, p. 15).

Em síntese, as epistemologias que creem ser o humano formado pelas imposições/coações do exterior alimentam o empenho na padronização no homem e na mulher moldados pelo ambiente. Pasillas (2005), chama nossa atenção para o fato de a educação historicamente ter sido âmbito de procedimentos coercitivos, sob o pretexto da inculcação da ordem, da obediência e das crenças "verdadeiras". Com a tomada de consciência da impropriedade dessa opção, ganha vida uma singela pergunta: Qual a vocação mais legítima do ser humano?

\section{Repensando caminhos epistemológicos e éticos}

A vocação mais legítima do humano é, como afirma Jacquard (1996, p. 123), para a autoria, não para a mera representação de papéis destinados a nós, por isso "a 
escola não deve servir para oferecer à sociedade os homens e as mulheres de que ela precisa, mas para possibilitar a cada um o acesso aos meios que lhe permitam construir a sua inteligência", isso aponta para a necessidade de mudança de norte epistemológico.

Alvarado (2007) lembra-nos de que a educação atual não superará a si mesma, se não se livrar da pesada âncora epistemológica que a impede de navegar livre por céus de novos mundos e de novos tempos. A cultura escolar revela-se reticente quando o desafio é a mudança de orientação epistemológica. Isto ocorre por ser refratária às incertezas próprias de um mundo em construção, por isso tende a preferir determinismos de diferentes matizes possibilitados pelo controle externo.

Transpondo o portal da pessoa determinada pela sociedade, uma possibilidade é enxergarmos o sujeito e a sociedade como seres autopoiéticos (MATURANA; VARELA, 1995). A ideia matriz dessa via é entender o conhecimento como ação no mundo e não representação do mundo.

Varela (1994) reitera que a cognição não é a representação de um mundo pré-dado por uma mente pré-dada, mas a construção de um mundo e de uma mente com base na história da variedade de ações que cada ser realiza. Assim, o mundo não é algo que tenha sido entregue a nós, ele emerge a partir de como nos movemos, tocamos, respiramos, comemos.

Esse autor esclarece que a ação predomina sobre a representação. Assim, defende uma compreensão de cognição que não se desvincule do senso-comum - nossa história física e social - sujeito e objeto são a especificação um do outro, emergindo na ação. Essa compreensão de cognição anuncia a poética da incerteza, no mundo da cognição inexistem percursos predeterminados.

Compartilhando a mesma compreensão, Gutiérrez (2010) situa a aprendizagem como processo da vida, que comporta auto-organização, incerteza e sustentabilidade. Nessa forma de entender, o viver é um processo de cognição e o conhecer é elemento essencial da autoconstrução dos seres vivos. Para esse pesquisador, isto consiste no processo de autopoiese de Maturana e Varela (1995), em que "auto" significa "si mesmo" e "poiese", que tem a mesma raiz grega que poesia, significa criação, que em essência se dá sempre no prazer.

Gutiérrez (2010) diz ser inconcebível uma criação não poética. Por isso, aprender dá origem a estados imprevisíveis em razão de que aprender não é armazenar conhecimento, mas integrar a informação que recebemos ao processo de autoconstrução pessoal. A aprendizagem que responde à auto-organização é necessariamente dinâmica, flexível, viva e consequentemente holística, complexa e política.

Kastrup, Tedesco e Passos (2008, p. 12) ampliam o universo de discussões sobre cognição ao discorrerem sobre políticas cognitivas. Eles esclarecem que o conceito de política cognitiva procura evidenciar que "o conhecer envolve uma posição em relação ao mundo e a si mesmo, uma atitude, um ethos”. Essa compreensão nos afasta da crença num mundo dado que apenas representamos, que coloca problemas que devemos solucionar. 
Esses autores descrevem duas políticas cognitivas: a da representação e a da invenção do mundo e de si mesmo. A cognição representacional e a cognição inventiva são dois modos de estar no mundo, de estabelecer relação consigo e com a própria atividade de conhecer. Sendo a invenção, "em seu sentido primordial, invenção de problemas, pois é a invenção de problemas que coloca a cognição em devir, sendo o primeiro passo para a invenção de si e do mundo" (KASTRUP, 1999, p. 2002).

Com vistas à superação da política cognitiva limitada à perspectiva representacional, Kastrup (2004, p. 122) aponta a necessidade da resistência no sentido positivo que "é a criação de uma outra atitude, de um outro ponto de vista, de uma outra política, de uma maneira de conhecer e de viver que prepara e é condição para a criação de novos mundos, a serem forjados caso a caso, através de estratégias concretas de ação".

Situando-se diante da concretude do cotidiano, Kastrup (2008, p. 122) esclarece que o "problema da ética não equivale à discussão dos códigos morais nem à questão do juízo moral", trata-se de "ação corporificada, inscrita corporalmente a partir da prática cognitiva em contextos específicos e domínios de interesses concretos" (KASTRUP, 2008, p. 122).

Cervantes (2014) argumenta que a sala de aula é um dos espaços formais de maior vitalidade e transcendência do humano, como pessoa e como membro da comunidade planetária. Porém, pergunta: Como estamos a conviver nesses espaços de tanta riqueza espiritual, afetiva e emocional? Para que estamos educando?

A própria Cervantes (2014) responde que precisamos reconhecer que vigora nesses espaços uma forma em que se valoriza a competência, o exterior e as aparências. As crianças chegam à escola submetidas ao espírito da competição pela família e pela sociedade em que vivem, por suas amizades, pelas expectativas das pessoas adultas. Isso ocorre em contraposição ao desejável, que seria uma prática marcada pela valorização do outro, da outra, a empatia, a cooperação, a contemplação da beleza e a harmonia com a natureza.

Cervantes (2014) aponta como desafio do sistema educativo favorecer a qualidade humana interior, cultivando a interioridade que nos identifica como seres vitais e planetários. Essa pesquisadora esclarece, ainda, que a realidade que enfrentamos no ato educativo é mutante, o mais permanente que a caracteriza é sua impermanência. Por isso, precisamos educar para interrogar a realidade em mudança cotidiana, para nos afastarmos das certezas que nos controlam.

Caminhando pelo mesmo universo, Krishnamurti (2001) assevera que a educação precisa encaminhar cada aluno ao conhecimento de si mesmo como fonte de renovação efetiva. Esse pensador assegura que, quando o mundo se revelar destrutivo e carente de significado, cabe às escolas se converterem em espaços de luz e sabedoria. Os horizontes escolares precisam ser convidativos à intensa vivacidade criadora.

Criação liga-se à ousadia da experimentação do ainda não conhecido, da imaginação desperta. A esse respeito, Andrade (2002, p. 19) diz que "a autoria de 
pensamento pressupõe espaços de liberdade que se constituem a partir da aceitação das diferenças e do prazer em pensar". É nesse clima que podemos pensar a cidadania como exercício de autoria, em que nossa posição não é de quem busca adaptação, mas de oposição criadora (BRANDÃO, 1985).

A mudança epistemológica, que tem por norte a autocriação tira a aura de soberania do ato de ensinar, colocamo-nos diante de capacidades que precisam ser aprendidas, contudo não há como ensiná-las nos moldes instrucionistas. Isso cobra do professor postura aberta ao diálogo e à humildade característica de quem compreende a impropriedade da educação sustentada pela comunicação verticalizada.

\section{Cotidiano, atenção e competência ética}

Uma tomada de consciência importante para o professor, independente do nível e da idade de seus alunos, é que há conteúdos que as pessoas precisam aprender e que, contudo, não podem ser ensinados. Destacamos, a título de exemplos, dois deles:

- A capacidade atencional - Nardin e Sordi (2007, p. 105) afirmam que tanto a capacidade atencional "quanto a de brincar se aprendem; porém, ninguém pode ensiná-las. Somente são possíveis na relação com um outro que acredita na capacidade pensante do sujeito, seja ele criança, jovem ou adulto”.

- A desenvoltura para ver - Esquirol (2008, p. 57), diante da pergunta: Como se aprender a olhar? Responde que se aprende "a olhar, olhando, assim como se aprende a pensar, pensando. O exercício é o primeiro mestre. Donde se pode dizer que não se aprende a visão senão de si mesma”.

Quando nossas atenções se voltam a aprendizagens necessárias, que não podem ser alcançadas por meio de ensino, percebemo-nos em um território onde "não existe conhecedor abstrato de uma experiência que seja separado da própria experiência" (SADE, 2009, p. 50). Este fragmento de "O guardador de rebanhos", de Alberto Caeiro (PESSOA, 1996, p. 146), parece retratar o clima cognitivo compatível com o exigido:

Sou um guardador de rebanhos.

O rebanho é os meus pensamentos

E os meus pensamentos são todos sensações.

Penso com os olhos e com os ouvidos

E com as mãos e os pés

E com o nariz e a boca.

Pensar uma flor e vê-la e cheirá-la

$\mathrm{E}$ comer um fruto é saber-lhe o sentido.

Compatível com o sentido de imersão corpórea retratado pelo poeta, Maturana e Varela (1995) esclarecem ser o corpo o instrumento que permite nossa acoplagem com o ambiente, e que a aprendizagem decorre desse acoplamento. 
A competência ética não se limita aos domínios teóricos, ela tem as raízes no cotidiano do ver, do cheirar, do manusear... Precisa ser aprendida, porém ninguém pode ensiná-la, pois se inscreve no rol de aprendizagens centradas na experiência vivida, no zelo com que sentimos, olhamos e escutamos as múltiplas vozes do mundo.

Nesse trilhar, Cedeño e Cedeño (2013, p. 117) afirmam que compreender o ruído e o lamento da terra não se ensina, se vive. Como docentes, temos a "responsabilidade de gerar momentos inumeráveis para escutar o que o ruído do tédio e da rotina não permitem, para olhar para além do que não se olha por estarmos cegos pela cultura escravizadora de memorização e fragmentação".

Essas pesquisadoras alertam que é difícil vivenciar a ética se a pedagogia não possibilita que as pessoas cresçam na compreensão dos demais, se as dinâmicas predominantes privilegiam a competição e a exclusão; se justificam a violência que vai desde a imposição de conteúdos até a avaliação por meio de exames e medições fundadas em estereótipos que anulam a identidade e a individualidade e a partir delas se constroem classificações das pessoas.

Cedeño e Cedeño (2013) reiteram que aprender é parte da relação dinâmica com a vida, que se caracteriza pela convivência e pelas inter-relações que potencializam a autorrealização à luz da criação compartida. Aprender na convivência não se consegue, senão no interior de um marco ético de interação em que a comunicação permite encontros marcados por diálogos atenciosos.

"O olhar atento é a condição para se orientar na vida" (ESQUIROL, 2008, p. 15), ele nos conecta firmemente com o mundo. Para esse autor, "quem presta mais atenção melhor se orienta e mais respeita" (2008, p. 15). Nessa perspectiva, olhar atento significa olhar ético.

Esquirol (2010) enfatiza que a liberdade não consiste em estar em dia, mas em ver e viver o dia. A escolha por ver o dia permitiria a passagem da impessoalidade para ser dono de si mesmo e prestar a devida atenção ao mundo. "A atrofia do senso moral acontece com a atrofia de nossa capacidade para estar no mundo e apreciar sua contínua mudança" (ESQUIROL, 2010, p. 67).

A competência ética implica nosso atento estar no mundo, pois a "atenção nos conecta com mundo e essa conexão é a melhor vacina contra dogmatismos, slogans, ideologias e linguagens, aparentemente técnicos, mas na realidade, vãos" (ESQUIROL, 2010, p. 68). Para esse pensador:

Graças à atenção, notamos o valioso, o bom e o belo deste mundo, enquanto que, distraídos, deixamos escapar as verdadeiras pérolas da vida como coisa sem importância. Simultaneamente, a atenção nos situa e nos orienta no mais fundamental: na percepção de nossa finitude, e em que a mais importante das virtudes é a humildade. (ESQUIROL, 2010, p. 92).

A competência ética emerge da própria vida, de nossa inserção no mundo, do cuidado com que vemos e ouvimos o mundo e a nós próprios, do zelo na autoria dos papéis que representaremos. Sua construção só é possível em clima de liberdade, respeito e diálogo; não pertence ao mundo discursivo, mas à vivência desperta. 


\section{Algumas conclusões}

Consciente ou inconscientemente, a ação educativa ancora-se em um sistema de crenças epistemológicas que orienta nosso olhar para o mundo e, principalmente, para nós próprios. O passeio por discussões educacionais reitera as profundas marcas que a opção epistemológica deixa na forma como nos situamos como seres éticos.

Nesse território ainda vivemos sob predomínio da persistente e empobrecedora crença que delega ao ambiente o protagonismo na formação ética sedimentada em crenças, dogmas, verdades e padrões. Por esse caminho epistemológico, criam-se ambientes verticalizados, arrogantes e com poder de coagir pela recitação de normas. O comportamento ético ditado pelo ambiente pronuncia-se pela obediência ao que "todos fazem".

A palavra-chave, nessa perspectiva, é adaptação. A educação, preocupada em adaptar as crianças à sociedade, acaba descrevendo o amanhã com olhos temerosos do não conhecido. Essa educação mostra nossas pobrezas - de todas as naturezas e dimensões - como coisas naturais. Prepara, assim, as crianças de hoje para não se indignarem amanhã diante das injustiças, das violências, das cegueiras de diferentes naturezas que embotam nossa atenção.

Quando entramos no território da horizontalidade - interior e exterior como vias que se entretecem, nossa posição de leitores do mundo ganha outra dimensão, de exigência maior, que cobra o olhar atento, a prontidão-para-ação, a sabedoria para a tomada de decisões de natureza ética.

Por essa via epistemológica, quando o assunto é competência ética em contextos educacionais, dialogamos com a humildade, descobrimos limites, conversamos sobre coisas que precisam ser aprendidas e que não podem ser ensinadas. Essa tomada de consciência aponta para a necessidade de o discurso sobre ética dar lugar à construção de um clima educativo de cuidadosa leitura das relações tecidas no cotidiano, fazendo emergir a possibilidade de um mundo em harmonia, convidativo ao olhar atento, ao estar presente curioso em conhecer e saborear cada momento bem vivido.

Vale lembrar que as verdades que carregamos atrofiam nossa sensibilidade, porque para dialogar com o mundo precisamos estar abertos a diferentes vozes, particularmente às que causam estranheza. Isso é possível quando percebemos que o conhecimento de si mesmo e do mundo é fruto do estar presente, do olhar ético.

Como síntese, o percurso apresentado levou-nos ao entendimento de que a crença no poder coercitivo do ambiente fomenta o espírito ético calcado na padronização, com forte adesão ao que parece ser moda. Por outro lado, a perspectiva atenta à interioridade, considera a competência ética como algo que se aprende praticando, vivendo, agindo eticamente. 


\section{Referências}

ALVARADO, E. Educación, ecología y economía: pasos hacia otra epistemología. Costa Rica, Centro América: Alma Mater, 2007.

BRANDÃO, C. R. A educação como cultura. São Paulo: Brasiliense, 1985.

BRIGGS, J.; PEAT, F. D. Sabedoria do caos. Rio de Janeiro: Campus, 2000.

CEDEÑO, I. C.; CEDEÑO, R. C. La mediación biopedagógica desde una perspectiva ética. Revista Electrónica Educare, Heredia, Costa Rica, v. 17, n. 2, p. 111-121, 2013. Disponível em: <http://www.una.ac.cr/educare>. Acesso em: 14 jun. 2014.

CERVANTES, G. M. La persona: Núcleo vital del proceso de mediación pedagógica. Revista Electrónica Educare, Heredia, Costa Rica, v. 18, n. 1, p. 293-301, 2014. Disponível em: <http:// www.una.ac.cr/educare >. Acesso em: 17 jul. 2014.

DELVAL, J. Crescer e pensar. Porto Alegre: Artes Médicas, 1998.

ESQUIROL, J. M. O respeito ou o olhar atento. Belo Horizonte: Autêntica, 2008.

O respirar dos dias. Belo Horizonte: Autêntica, 2010.

FREIRE, P. Pedagogia do oprimido. Rio de Janeiro: Paz e Terra, 1981.

FREITAG, B. Piaget depois de 100 anos: dentro ou fora de moda? In: LIMA, L. O. Piaget: sugestões aos educadores. Petrópolis: Vozes, 1999. p. 11- 26.

GUTIÉRREZ, F. Las nuevas ciencias de la vida. Polis, Santiago, v. 9, n. 25, p. 223-233, 2010. Disponível em: <www.scielo.cl/pdf/polis/v9n25/art12.pdf>. Acesso em: 13 abr. 2014.

JACQUARD, A. Acuso a economia triunfante. Lisboa: Publicações Europa-América, 1996.

Inventar o homem. Lisboa: Terramar, 1990.

KASTRUP, V. A aprendizagem da atenção na cognição inventiva. Psicologia \& Sociedade, Porto Alegre, v. 16, n. 3, p. 7-16, set./dez. 2004. Disponível em: <http://www.scielo.br/pdf/psoc/ v16n3/a02v16n3.pdf >. Acesso em: 20 maio 2013.

KASTRUP, V. A invenção de si e do mundo. Campinas: Papirus, 1999.

Estratégias de resistência e criação. In: GUARESCHI, N. Estratégias de invenção do presente. Rio de Janeiro: Centro Edelstein de Pesquisas Sociais, 2008. p. 120-130.

KASTRUP, V.; TEDESCO, S.; PASSOS, E. Políticas da cognição. Porto Alegre: Sulina, 2008.

KRISHNAMURTI, J.A educação e o significado da vida. São Paulo: Cultrix, 2001.

MATURANA, H.; VARELA, F. A árvore do conhecimento. Campinas: Psy, 1995.

MORIN, E. Introdução ao pensamento complexo. Lisboa: Instituto Piaget, 1991.

NARDIN, M. H.; SORDI, R. Um estudo sobre as formas de atenção na sala de aula e suas implicações para a aprendizagem. Psicologia \& Sociedade, Porto Alegre, v. 19, n. 1, p. 99-106, jan./abr. 2007. Disponível em: <http://www.scielo.br/pdf/psoc/v19n1/a14v19n1.pdf>. Acesso em: 11 maio 2014.

PASILLAS, M. A. Violencia, ética y pedagogia. Revista Mexicana de Investigación Educativa, v. 10, n. 27, p. 1149-1164, oct.-dic. 2005. Disponível em: <http://www.redalyc.org/articulo. oa?id=14002711>. Acesso em: 12 ago. 2014.

SADE, C. Enação e metodologias de primeira pessoa: o reencantamento do concreto das investigações da experiência. Informática na Educação: teoria \& prática, Porto Alegre, v. 12, n. 2, p. 45-58, 2009. Disponível em: < http://seer.ufrgs.br/index.php/InfEducTeoriaPratica/article/ view/9604/7240>. Acesso em: 13 jun. 2014. 
SAVATER, F. Ética para meu filho. São Paulo: Martins Fontes, 1996.

VARELA, F. Conhecer: as ciências cognitivas tendências e perspectivas. Lisboa: Instituto Piaget, 1994.

Sobre a competência ética. Lisboa: Edições 70, 1995.

VARELA, F.; THOMPSON, E.; ROSCH, E. A mente corpórea. Lisboa: Instituto Piaget, 1993.

* Professor doutor da Universidade do Oeste Paulista, Presidente Prudente, São Paulo, Brasil.

\section{Correspondência}

Adriano Rodrigues Ruiz - Universidade do Oeste Paulista, Mestrado em Educação. Rodovia Raposo Tavares, km 572, Limoeiro, CEP: 19067-175 - Presidente Prudente, São Paulo - Brasil.

E-mail: arruiz@uol.com.br

Recebido em 03 de março de 2015

Aprovado em 06 de maio de 2015 